\title{
The design for 18/12 Pole of External Rotor Doubly Salient Permanent Magnet Wheel Motor for Electric Vehicle
}

\author{
Wang Haiyang ${ }^{1, \mathrm{a}}, \mathrm{Ge} \mathrm{Qi}^{2, \mathrm{~b}}$ \\ ${ }^{1,2}$ School of Electrical Engineering, Zhengzhou University, Zhengzhou 471000 China \\ awanghaiyangjinmu@126.com, b376132431@qq.com
}

Keywords: doubly salient, permanent magnet motor, Ansoft, load analysis.

\begin{abstract}
The paper,taking a Honda SUV vehicle tires as an example,designed a outer rotor 18/12 pole doubly salient permanent magnet wheel motor and briefly introduced the design principles for the motor size and the material selection for the main part of the motor . This paper also used Ansoft software to do the motor no-load finite element analysis,verified that the motor design is reasonable, and derived the switch conduction order for the motor drive circuit by the use of no-load motor flux curve . this laid the foundation for the motor load analysis.
\end{abstract}

\section{Introduction}

In recent years, as people's living standards continue to improve, the demand for cars was a spurt of development. According to China Association of Automobile Manufacturers data statistics, in 2015 China car sales reached 2,459.76 million units. however ,the contradiction between the development of automobile industry and energy and environment is becoming more and more serious [1]. The traditional car is mainly based on the fuel car, whose energy consumption directly causes environmental pollution, and it is also the main cause of the global oil crisis.under the pressure of environmental protection and energy crisis, governments, research institutions and automobile manufacturers have to invest a lot of manpower and financial resources to develop new high-performance and environmentally friendly zero-emission electric vehicles. However, as one of the key technologies in the research of electric vehicle,the wheel motor technology is expected to become the main force of electric vehicles in the future. On the basis of reading a lot of literature and analyzing the relevant knowledge of automobile tire,this paper, taking a Honda SUV vehicle tires as an example,designed a outer rotor 18/12 pole doubly salient permanent magnet wheel motor and used Ansoft software to do the motor no-load finite element analysis.

\section{Motor design}

In this paper, the model of the tire model for R17 225/65,it represents a wheel width of 225mm, the wheel height to width ratio of $65 \%$, wheel diameter of 17 inches $(432 \mathrm{~mm})$. Wheel hub motors are generally mounted on a wheel, and the motor diameter is generally smaller than the diameter of the hub. Since the hub diameter of 17 inches $(432 \mathrm{~mm})$, In order to facilitate the installation, the outer diameter of the outer rotor of the motor $D_{\text {ro }}$ is $410 \mathrm{~mm}$. The ratio of outside diameter and inside diameter of the rotor is between $0.4 \sim 0.7$, taking into account the stator yoke needs to be placed on the permanent magnet steel and the stator should be more than enough space, so choose $D_{r i} / D_{r o}=0.7$, the inner diameterthe of outer rotor $D_{r i}=287 \mathrm{~mm}$. Further, in this case the thickness of the gap $\mathrm{g}$ is taken $0.5 \mathrm{~mm}$, so the diameter of the stator $D_{s o}=D_{r i}-2 \mathrm{~g}=286 \mathrm{~mm}$.

\subsection{The Selection of The Stator Size.}

To ensure that the synthesis air gap magnetic conductance is constant and avoid the positioning torque generated, the stator pole arc take $10^{\circ}$, the tooth width of the stator is equal to the slot width of the stator . the tooth width of the stator is calculated as follows[2]: 


$$
W_{S}=\frac{\pi D_{s o}}{2 * 18}\left(D_{\text {so }}=286 m m\right)
$$

so the tooth width and slot width of the stator is about $25 \mathrm{~mm}$.

The relationship between the height of the stator yoke and the tooth width of The stator is calculated as follows:

$$
h_{e s} \succ(1.2 \sim 1.4) \frac{b_{p s}}{2}\left(b_{p s}=25 \mathrm{~mm}, \text { the factor for } 1.4\right)
$$

so the yoke height of the stator is about $18 \mathrm{~mm}$.

The tooth heightof the stator is calculated as follows:

$$
h_{c s}=\frac{D_{s o}-R_{Z}}{2}-h_{e s}\left(D_{s o}=286 \mathrm{~mm}, R_{z}=150 \mathrm{~mm}, h_{e s}=18 \mathrm{~mm}\right)
$$

so the tooth height of the stator is about $50 \mathrm{~mm}$.

\subsection{The Selection of The Rotor Size.}

To suppress the rotation pulse, it is general that the rotor tooth width is equal to the stator tooth width when designing the rotor. So the rotor tooth width is $25 \mathrm{~mm}$.

The rotor slot width is calculated as follows:

$$
W_{r}=\frac{\pi D_{s o}}{12}-W_{p} \quad\left(D_{\text {so }}=286 m m, W_{p}=25 m m\right)
$$

so the rotor slot width is about $50 \mathrm{~mm}$.

The relationship between the height of the rotor yoke and the tooth width of The rator is calculated as follows:

$$
h_{e r} \succ(1.2 \sim 1.4) \frac{w_{p}}{2}\left(w_{p}=25 \mathrm{~mm} \text {, the factor for } 1.4\right)
$$

So the yoke height of the rotor is about $18 \mathrm{~mm}$.

The function of the rotor tooth height is :

$$
h_{c r}=\frac{D_{r o}-D_{r i}}{2}-h_{e r}\left(D_{r o}=410 \mathrm{~mm}, D_{r i}=287 \mathrm{~mm}, h_{e r}=18 \mathrm{~mm}\right)
$$

so the tooth height of the rotor for about $43.5 \mathrm{~mm}$.

\subsection{The Selection of The Permanent Magnet Size.}

In general, the length of the permanent magnet is equal to the length of the motor.But the section of height and width should be determined according to the formula of electromagnetic design, the function is[3,4]:

$$
\left\{\begin{array}{l}
H_{p m}=\frac{2 B_{\delta} g_{0}}{\mu_{0} H_{c}\left(1-\frac{B_{m}}{B_{r}}\right)} \\
W_{p m}=\sigma \frac{B_{\delta} D_{s i}}{4 B_{m}}\left(2 \beta_{s}+\beta_{r}+\theta_{c r}-2 \theta_{c s}\right)
\end{array}\right.
$$

Among the function, $g_{0}$ represents the gap length; $\mu_{0}$ represents the Air gap permeability; $B_{r}$ and $H_{c}$ represents the density of the permanent magnet remanence and the coercivity; $B_{m}$ and $B_{\alpha}$ represents the magnetic flux density and magnetic load at the working point of the permanent magnet; $\beta_{r}$ and $\beta_{s}$ represents the stator and rotor poles; $\theta_{c s}$ and $\theta_{c r}$ says the stator and rotor pole angle; $\sigma$ represents leakage coefficient. So , $w_{p m}=28 \mathrm{~mm}, h_{p m}=18 \mathrm{~mm}$.

In summary, the size of the motor is shown in the following Table 1: 
Table 1 The Motor Size $(\mathrm{mm})$

\begin{tabular}{c|ccccc}
\hline \multirow{2}{*}{ Rotor } & Outer diameter & inner diameter & Tooth height & yoke height & Pole arc \\
\cline { 2 - 6 } & 410 & 287 & 43.5 & 18 & $10^{\circ}$ \\
\hline \multirow{2}{*}{ stator } & Outer diameter & Shaft diameter & Tooth height & yoke height & Pole arc \\
\cline { 2 - 6 } & 286 & 150 & 50 & 18 & $10^{\circ}$ \\
\hline \multirow{2}{*}{$\begin{array}{c}\text { Permanent } \\
\text { magnets }\end{array}$} & width & height & & & \\
\cline { 2 - 6 } & 28 & 18 & & & \\
\hline
\end{tabular}

\section{Characteristics of No-load}

According to Table 1, the motor configuration diagram is shown in Fig. 1.

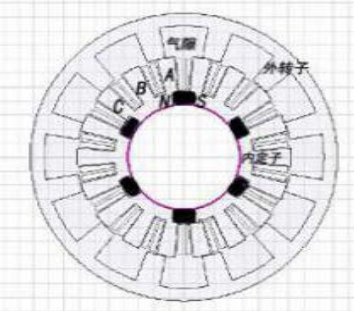

Fig. 1 The Motor Configuration Diagram

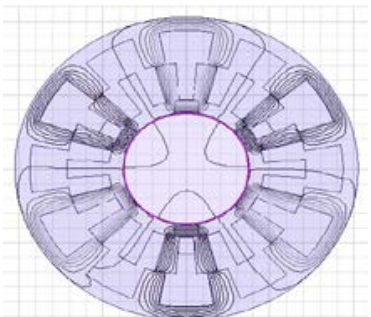

Fig. 2 The Distribution Diagram of The

Lines of Magnetic Force In No-load

As shown in Fig. 2 for the distribution diagram of the lines of magnetic force in no-load only when the Permanent magnet effect. From the figure, we can know that there are some magnetic flux leakage, but it has not much impact to the main magnetic flux. Therefore, the design of the motor magnetic circuit is reasonable.

As shown in Fig. 3 for the magnetic induction intensity diagram in no-load, the different colors indicate different values of magnetic induction intensity. From the figure ,we can see the magnetic induction intensity of different parts of motor[5,6]. So the design of the motor is basically reasonable.
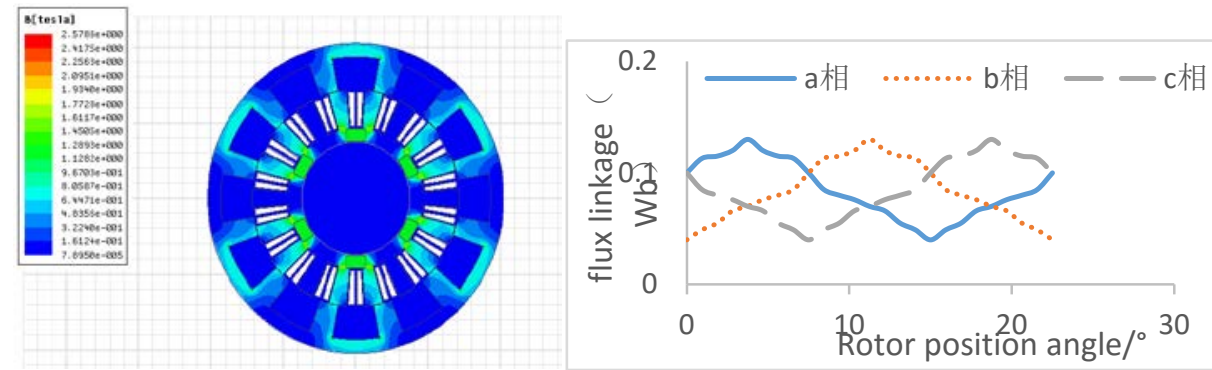

Fig. 3 The Magnetic Induction Intensity

Fig. 4 The Three-phase Flux Linkage Diagram Diagram

As shown in Fig. 4 for the three-phase flux linkage diagram in no-load .The winding flux characteristics directly determine the power-on time of the winding, And the power-on time of the winding directly affects the running state of the motor and the size of the torque ripple. The motor drive circuit diagram is shown in Fig. 5. According to the principle that the winding is given the positive phase current when the flux rises and the winding is given the negative phase current when the flux declines, We can set the Turn-on sequence of each winding switch [7],it is shown in the Table 2 . 
Table 2 The Turn-on Sequence of Each Winding Switch

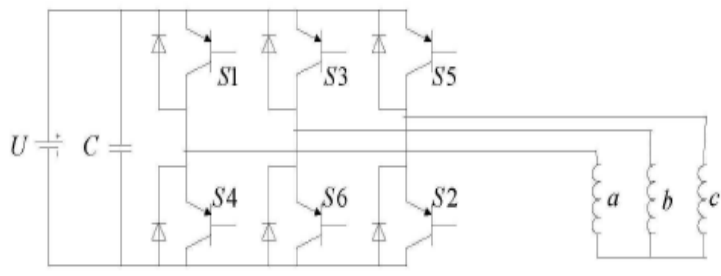

\begin{tabular}{cc}
\hline Rotor angle position & Open switch \\
\hline $0-3.75^{\circ}$ & S1、S2 \\
$3.75-11.25^{\circ}$ & S3、S4 \\
$11.25-18.75^{\circ}$ & S5、S6 \\
$18.75-22.25^{\circ}$ & S1、S2 \\
\hline
\end{tabular}

Fig. 5 The Motor Drive Circuit Diagram

\section{Conclusions}

This paper describes the section of the size of the main parts of the motor and uses Ansoft software to do the motor no-load finite element analysis, showing the rationality of the design of the motor. By the no-load flux characteristics of the motor, We can set the Turn-on sequence of each winding switch and it lays a solid foundation for the motor load characteristic analysis.

\section{References}

[1]Wang Da-zhi. the finite element analysis of doubly salient wheel motor for electric vehicle[D]. South China University of Technology, 2014.

[2]Lin Yao-ming, Cheng Ming, Zhou e. Design and analysis of a new12/8-pole doubly salient permanent-magnet motor[J]. Journal of Southest University, 2002.

[3]Tang Ren-yuan. Modern Permanent Magnet Machines[D]. Machinery Industry Press, 2012.

[4]Wang Xiu-he. Permanent Magnet Machines[D]. China Electric Power Press, 2011.

[5]Liu Guo-qiang, Zhao Ling-zhi, Jiang Ji-ya. Ansoft- engineering electromagnetic field analysis software[D]. Publishing House of Electronic Industry, 2005.

[6]Zhao Bo, Zhang Hong-liang. Application of Ansoft 12 in engineering electromagnetic field[D]. China Water Conservancy and Hydropower Publishing House, 2013.

[7]Xu An-ju. Analysis on Steady Characteristic about Doubly Salient Permanent Magnet wheel-hub Motor used for electric vehicle driving system[D]. South China University of Technology, 2012. 